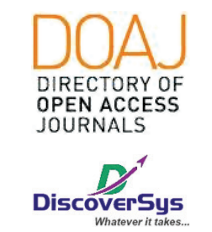

Published by DiscoverSys

\section{The level of knowledge regarding breast cancer among female high school students at Santo Yoseph School, Denpasar, Bali, Indonesia}

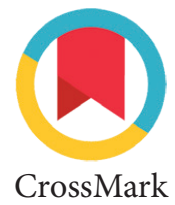

\author{
Hemalatha Thiruchelvam, ${ }^{1 *}$ Ni Nyoman Ayu Dewi, ${ }^{2}$ Ida Ayu Dewi Wiryanthini ${ }^{2}$
}

\title{
ABSTRACT
}

Background: Breast cancer is the second leading cause of death among women around the world. In Indonesia, breast cancer is the leading cause of death among women. Previous studies have shown that female students have limited knowledge of breast cancer. This study is aimed at assessing the level of breast cancer knowledge among female high school students in Santo Yoseph School, Denpasar. Methods: A cross-sectional survey of 96 female high school students in Santo Yoseph School, Denpasar, was conducted using a self-administered questionnaire. Questions asked in the questionnaire were about general knowledge of breast cancer, risk factors towards breast cancer, signs and symptoms of breast cancer and knowledge of Breast Self-Examination. The data was tabulated by scoring only the correct answers and analysed using SPSS version 17 for Windows.

Results: The result of the study showed that high school female students had moderate to good knowledge of breast cancer. Fiftythree (55.2\%) female students had average knowledge and fortythree (44.8\%) female students had good knowledge of breast cancer. The majority of the participants, seventy-five (78.1\%) of them, knew that breast cancer was the leading cause of death among women in Indonesia.

Conclusion: The recent findings showed that female high school students had good knowledge of breast cancer. Good knowledge of breast cancer is important for girls and women equally.
'Undergraduate Student, Faculty of Medicine, Udayana University, Bali, Indonesia ${ }^{2}$ Department of Biochemistry, Faculty of Medicine, Udayana University, Bali, Indonesia
*Correspondence to: Hemalatha Thiruchelvam; Undergraduate Student, Faculty of Medicine, Udayana University, Bali, Indonesia;

emmawat96@gmail.com

Received: 2019-03-25 Accepted: 2019-10-11 Published: 2019-12-01
Keywords: Breast Cancer, knowledge, female high school students Cite This Article: Thiruchelvam, H., Dewi, N.N.A., Wiryanthini, I.A.D. 2019. The level of knowledge regarding breast cancer among female high school students at Santo Yoseph School, Denpasar, Bali, Indonesia. Intisari Sains Medis 10(3): 637-642. D0I: 10.15562/ism.v10i3.459

\section{INTRODUCTION}

Breast cancer is the second most leading death of women in the world. Breast cancer is most common among women however in some rare cases men would also be diagnosed with it. Breast cancer begins when the cells in women start growing abnormally. This growth is also known as malignant growth, and they may metastasise to other parts of the body which may lead to high risk of mortality. ${ }^{1}$ The most common cancer among women in the United States is invasive breast cancer. ${ }^{1}$

Breast cancer is currently on the rise in Asian countries. Based on research conducted by International Agency on Research in Cancer, involving two Asian countries Malaysia and Indonesia, it has found that the highest cancer prevalence among women in these countries is breast cancer. These two particular countries were used in this research as they have almost similar cultural background and lifestyle. The study has also reported that females' who suffer from breast cancer have a young mean age. ${ }^{2}$ A previous study also mentioned that subtype of breast cancer in young females related to haematological parameters. $^{3}$
The World Health Organization has also carried out a study on each country's cancer profile around the world. Based on the study conducted in Indonesia, it shows that female suffering from breast cancer is highest compared to other cancer in both male and female. ${ }^{4}$ The study by World Health Organization-Cancer Country Profiles in Indonesia in 2014, came up with the statistic of $21.4 \%$ which breast cancer contribute to the highest mortality rate with young female above the age of 20 becoming the victims. ${ }^{4}$

A cross-sectional descriptive study conducted in Nigeria among female health workers shows that the majority of them had poor knowledge of breast cancer. ${ }^{5}$ However, in Pakistan it showed that nurses had good knowledge of breast cancer. ${ }^{6}$ Young breast cancer patients are found to have lower survival rate to those of higher age. This increases the importance of breast cancer knowledge among female high school students. A research conducted among female high school students in Turkey shows that those students had insufficient knowledge about breast cancer. ${ }^{7}$ A study was conducted in Sri Lanka targeting adolescent school girls with questions such as risk factors, early warning signs 
and Breast Self-Examination being asked in the questionnaire. It was found that their knowledge of breast cancer was unsatisfactory. ${ }^{8}$ A positive outcome was also found in Nigeria where the level of awareness towards breast cancer among secondary school was commendably high. The mass media had a vital role in spreading awareness. However, breast cancer awareness did not promise good knowledge of breast cancer risk factors among these students. ${ }^{9}$

The community, especially women should be aware of this disease especially the risk factors to start preventative measures. The authors chose female high school students due to female students should have strong knowledge on breast cancer for them to be able to convey it to the public and practice preventive measures in their lives. Furthermore, based on some studies conducted around the world, it was found that overall, breast cancer knowledge is still considerably low among school students. Thus, it is essential to study their knowledge of breast cancer to help determine the next step in educating them.

\section{METHODS}

A descriptive study using a cross-sectional approach has been conducted to determine the level of breast cancer knowledge among 96 female high school students from Santo Yoseph School in Denpasar using a purposive sample sampling technique methods. The inclusion criteria of this investigation were, the participants that were selected for the study were aged between 16 to 18 years old, female, and joined the study by

Table 1 Baseline characteristics of participants

\begin{tabular}{lcc}
\hline Class & Female Students $\mathbf{( N = 1 1 8 )}$ & $\begin{array}{c}\text { Female Respondents } \\
(\mathbf{N}=\mathbf{9 6}) \mathbf{( \% )}\end{array}$ \\
\hline XI MIA/IPA - 1 & 22 & $19(19.79)$ \\
XI MIA/IPA - II & 20 & $16(16.67)$ \\
XI MIA/IPA - III & 19 & $18(18.75)$ \\
XI MIA/IPA - IV & 18 & $16(16.67)$ \\
XI MIA/IPA - V & 20 & $14(14.58)$ \\
XI MIA/IPA - VI & 19 & $13(13.54)$ \\
\hline
\end{tabular}

Table 2 The level of knowledge towards Breast Cancer among students

\begin{tabular}{lcc}
\hline Total Score & Level of Knowledge & $\mathbf{n}(\%)$ \\
$0-7$ & Poor & 0 \\
$8-15$ & Moderate & $30(31.25)$ \\
$16-23$ & Good 66 & $(68.75)$ \\
\hline
\end{tabular}

signing informed consent. The level of knowledge was classified as 1) Poor (0-10); 2) Moderate (11-17); 3) Good (18-23).

Questionnaires were given to female students to be answered. The respondents had to answer the questions honestly based on their knowledge and understanding. The questionnaires and respondents' information were kept confidential and was used for research. The female students were given one day, and they were allowed to bring home the questionnaire to answer the questions. The questionnaires were distributed to the female students on day one and collected on the next day.

The data from the questionnaires were collected, analysed and categorised by counting the number of people, based on their level of knowledge on breast cancer from poor knowledge to good knowledge. All data were analysed using the Statistical Package for the Social Sciences (SPSS) version 17.

\section{RESULTS}

The majority of the participants were aged 16 years old with seventy-six (79.2\%) of them, followed by seventeen (17.7\%), 17 years old participants and lastly the least is 18 years old with only three (3.1\%) of them participating in the questionnaire research (Table 1). The data were collected from the questionnaire that was handed out to 96 female high school students in class eleven of Santo Yoseph High School.

The level of Breast Cancer Knowledge of the students was classified as shown in the table below (Table 2). The overall total score on the knowledge of breast cancer was moderate with thirty $(31.25 \%)$ respondents proved to have reasonable knowledge towards breast cancer. Sixty (68.75\%) respondents showed to have good knowledge of breast cancer. The analysis showed that none of the participants had inadequate knowledge of breast cancer (Table 2).

Thirty- eight (39.6\%) respondents wrongly believed that only females are affected by breast cancer. The majority of the respondents, which is fifty-eight $(60.4 \%)$ had knowledge that breast can affect both male and female. Ninety-five (99.0\%) respondents answered correctly to the question of whether breast cancer is a communicable disease or not. Only one (1.0\%) respondent did not know that breast cancer is not a communicable disease. A vast majority of respondents, seventy-five (78.1\%) of them knew that breast cancer is the leading cause of death among Indonesian women. However, twenty-one $(21.9 \%)$ of the denied on it (Table 3 ). 
Table 3 Research questionnaires to the participants

\begin{tabular}{|c|c|c|c|}
\hline Item t & $\begin{array}{c}\text { Correct } \\
\text { n (\%) }\end{array}$ & $\begin{array}{c}\text { Incorrec } \\
\text { n (\%) }\end{array}$ & $\begin{array}{c}\text { Don't Know } \\
\text { n (\%) }\end{array}$ \\
\hline \multicolumn{4}{|l|}{ General knowledge } \\
\hline Only females are affected by breast cancer & $58(60.4)$ & $38(39.6)$ & \\
\hline Breast cancer is not a communicable disease & $95(99.0)$ & $1(1.0)$ & \\
\hline Breast Cancer is the leading cause of death in Indonesian women & $75(78.1)$ & $21(21.9)$ & \\
\hline \multicolumn{4}{|l|}{ Knowledge of breast cancer risk factors } \\
\hline Old age & $31(32.3)$ & $65(67.7)$ & \\
\hline Family history of breast cancer & $90(93.8)$ & $6(6.3)$ & \\
\hline Smoking 68 & $(70.8)$ & $28(29.2)$ & \\
\hline Breast size & $75(78.1)$ & $21(21.9)$ & \\
\hline Breastfeeding & $73(76.0)$ & $23(24.0)$ & \\
\hline \multicolumn{4}{|l|}{ Knowledge of signs and symptoms of breast cancer } \\
\hline Painless breast lump & $84(87.5)$ & $12(12.5)$ & \\
\hline Nipple discharge & $71(74.0)$ & $25(26.0)$ & \\
\hline Change in breast shape & $64(66.7)$ & $32(33.3)$ & \\
\hline Pain in the breast area & $75(78.1)$ & $21(21.9)$ & \\
\hline Changes in the area of breast skin & $50(52.1)$ & $46(47.9)$ & \\
\hline \multicolumn{4}{|l|}{ Knowledge of breast self examination } \\
\hline Breast Self- Examination is a method of early detection of breast cancer & $92(95.8)$ & $4(4.2)$ & \\
\hline At what age should Breast Self-Examination have started & $84(87.5)$ & $3(3.1)$ & $9(9.4)$ \\
\hline How often is Breast-Self Examination done & $35(36.5)$ & $25(26.0)$ & $36(37.5)$ \\
\hline When is the best time to do Breast Self-Examination & $40(41.7)$ & $3(3.1)$ & $53(55.2)$ \\
\hline Who carries out Breast Self-Examination & $83(86.5)$ & $4(4.2)$ & $9(9.4)$ \\
\hline Breast Self-Examination should be conducted in front of the mirror & $77(80.2)$ & $19(19.8)$ & \\
\hline Feel the breast area during Breast Self- Examination & $94(97.9)$ & $2(2.1)$ & \\
\hline Feel the armpits area during Breast Self-Examination & $47(49.0)$ & $49(51.0)$ & \\
\hline \multicolumn{4}{|l|}{ What is to be done when there are abnormalities during } \\
\hline Breast Self-Examination & $88(91.7)$ & $8(8.3)$ & \\
\hline What are the benefits of Breast Self-Examination & $88(91.7)$ & $8(8.3)$ & \\
\hline
\end{tabular}

The next category on breast cancer knowledge was knowledge of the risk factors of breast cancer. A significant majority of respondents, sixty-five $(67.7 \%)$ answered that old age is not a risk factor of breast cancer. However, ninety (93.8\%) of them knew that family history was a major contributory risk factor towards breast cancer. Sixty -eight $(70.8 \%)$ respondents answered correctly that smoking is a risk factor of breast cancer. Seventy-five (78.1\%) respondents knew that breast size does not have a role in risk of breast cancer and seventy-three $(76.0 \%)$ of them knows that breastfeeding does not increase the risk of breast cancer.

In general, the knowledge of the respondents towards the signs and symptoms of breast cancer was good based on the number of correct answers to the questions. Eighty-four (87.5\%) of the respondents knew that painless breast lump is a sign a symptom of breast cancer. Seventy-one (74.0\%) respondents knew that another sign and symptom of breast cancer was nipple discharge and seventy-five $(78.1 \%)$ of them answered correctly, that pain in the breast area is also a sign and symptom of breast cancer. In addition, the respondents were also aware that a change in breast shape and a change in the skin at the breast area were also a sign and symptom of breast cancer as sixty-four (66.7\%) and fifty (52.1\%) of them answered correctly for the particular questions.

The fourth and last category on the questions on breast cancer knowledge was on Breast SelfExamination (BSE). For some of the questions in this section, most of the respondents were unaware of Breast-Self Examination. A majority of respondents, 
ninety-two (95.8\%) of them had knowledge and knew that Brest Self-Examination is a method of early detection of breast cancer and eighty-four $(87.5 \%)$ of the respondents knew the right age when BSE should be started (Table 3). However, a considerable number of respondents did not know how often and when is the best time to carry out Breast Self-Examination. Thirty-six (37.5\%) and fifty-three (55.2\%) of the respondents answered 'Don't Know/ Unsure' to the particular question. Eighty-three (86.5\%) of them knew who should carry out BSE although a minority of the answered wrongly and 'Don't Know' (Table 3).

Most of the respondents knew how to conduct a Breast Self-Examination. Seventy-seven (80.2\%) of them knows that BSE should be performed in front of the mirror and ninety-four (97.9\%) of them knew correctly that they need to feel their breasts during a BSE. The question on feeling the armpits during a BSE was a close call, with fortynine $(51.0 \%)$ of them answered wrongly that you do not need to feel the armpits and with a difference of $2.0 \%$, forty-seven $(49.0 \%)$ of the answered correctly saying that there is a need to feel the armpits during BSE. The question on the necessary steps that need to be taken when there are abnormalities during a Breast Self-Examination and the benefits of Breast Self-Examination has an equal majority of correct answers, eighty-eight (91.7\%) (Table 3).

\section{DISCUSSION}

The current study aimed to find out the level of breast cancer knowledge among female highs school students from Santo Yoseph School, Denpasar. The findings in this questionnaire-based research show that the results in the previous studies were contrary to those in this research. In the present study conducted among female high school students, it is shown that they have moderate to good knowledge of breast cancer. This is opposite to the research or pilot studies conducted in Turkey and Sri Lanka, which showed that adolescent and high school girls have significantly poor knowledge towards breast cancer. $^{10}$

These differences could be due to the type of school this research was conducted and the number of student population this research was conducted. Whereby, the students were from a private school with proper primary education and regular exposure to health needs and benefits.

The good knowledge towards breast cancer does not mean that the female students have good in-depth knowledge of breast cancer and its associated factors such as risk factors, signs, symptoms, and knowledge on Breast Self-examination. Based on the study, it was found that the respondents as majority of them had slightly poor knowledge towards Breast Self- Examination. This finding was consistent with several studies in Nigeria, Turkey, Saudi Arabia and Egypt.

A descriptive and cross sectional study was conducted among high school students in Turkey. The results of the study showed that the students (62.1\%) had insufficient knowledge towards breast cancer, especially on Breast Self-Examination. Majority of the students had never heard of BSE, and most of them had little knowledge on the risk factors of breast cancer.?

The level of breast cancer knowledge among young females in Saudi Arabia was found to be limited based on research conducted there. An estimated $40 \%$ of the study population was found to have poor knowledge on Breast Self-Examination. However, their knowledge on breast cancer risk factors was good whereby most of them knew that older age and positive family history of breast cancer are contributing factors. ${ }^{11}$

The study in Egypt shows that $80 \%$ of women had limited knowledge of breast cancer. They found that females in the professional job had lower knowledge of breast cancer. This was compared with a study that was conducted in Malaysia among female school teachers. Egyptian female from a younger age group was said to have better knowledge compared to those from the older age group. ${ }^{12}$

A research conducted in Nigeria among undergraduates showed that the respondents had a low level of knowledge towards breast self -examination. The finding showed that the respondents either did not conduct Breast Self-Examination or were carrying it out wrongly. The low level of knowledge towards BSE was found to be because only about $18.3 \%$ of the respondents cared to seek information on BSE. ${ }^{13}$

Based on general knowledge about breast cancer, breast cancer takes up about $16 \%$ of all female cancers and is more common in women than men. ${ }^{11}$ The majority of the female students were aware that breast cancer affects both men and women $(60.4 \%)$, that breast cancer is not a communicable disease (99.0\%) and that it also the leading cause of death among Indonesian women (78.1\%). The female high school students had good general knowledge about breast cancer. ${ }^{11}$

Family history with breast cancer contributes about $10 \%$ of breast cancer in western countries. Old age and menopausal age also plays an important role in women in increasing the risk of breast cancer. ${ }^{14}$ Regarding knowledge on breast cancer risk factors, the majority of participants (93.8\%) knew that family history or having a close family 
member poses a risk or threat towards breast cancer. Based on research conducted in Jeddah, $80 \%$ of their students failed to recognise that family history imposes a high risk towards breast cancer. ${ }^{15}$ This is the total opposite to the female students from Santo Yoseph where they proved to have good knowledge associated with family history and breast cancer risk factors. Also $70.8 \%$ of the participants were aware that social habits such as smoking is a risk factor of breast cancer. However, their knowledge of old age as a risk factor of breast cancer was significantly low.

Breast cancer presents most commonly as a painless breast lump and a smaller proportion with non-lump symptoms. ${ }^{16}$ In this study, it was also proved that the participants had good significantly high knowledge on the signs and symptoms of breast cancer with $87.5 \%$ knowing that painless lump was also a sign apart from the pain in the breast area, nipple discharge and others. A study conducted in Iran showed that only $44 \%$ of the participants knew that painless lump is a common symptom of breast cancer. And even fewer of them knew that nipple discharge (6\%) and nipple retraction $(5 \%)$ were also warning signs of breast cancer. $^{10}$

Early detection of breast cancer is crucial in reducing mortality rates and improving the patient's prognosis and quality of life. ${ }^{10}$ The low survival rates in less developed countries are due to lack of early detection programmes. ${ }^{9}$ Based on the study conducted among high school and college students in Saudi; it was found that approximately $40 \%$ of the research targets had poor knowledge on Breast Self-Examination. ${ }^{11}$

Knowledge on Breast Self-Examination as a method of early detection of breast cancer was high among Santo Yoseph High School female students, $95.8 \%$. However, in this research less than half of the female participants (37.5\%), did not know the frequency to conduct Breast Self-Examination and the best time to carry it out. Nevertheless, they knew the essential steps that need to be done during a Breast Self-Examination. The participants also knew about what was to be done when there were abnormalities during a BSE and the benefits of BSE.

\section{CONCLUSION}

Based on the findings in this study, we can conclude that the female high school students from class eleven have moderate to good knowledge towards breast cancer, and none of them had poor knowledge towards breast cancer. These findings signify that a large number of students takes health seriously and are aware of the importance of learning and education of breast cancer.

\section{CONFLICT OF INTEREST}

There is no competing interest regarding the manuscript

\section{ETHICS CONSIDERATION}

This study has been received ethical approval from the Ethics Committee of Faculty of Medicine, Universitas Udayana, Bali, Indonesia.

\section{FUNDING}

None

\section{AUTHOR CONTRIBUTION}

All of authors are equally contribute to the study from the conceptual framework until reporting the results of study.

\section{REFERENCE}

1. Abdulkareem IH. Aetio-pathogenesis of breast cancer. Niger Med J. 2013; 54(6):371-375.

2. Ng CH, Pathy NB, Taib NA, Teh YC, Mun KS, Amiruddin $\mathrm{A}$, et al. Comparison of breast cancer in Indonesia and Malaysia--a clinico-patholog cal study between Dharmais Cancer Centre Jakarta and University Malaya Medical Centre, Kuala Lumpur. Asian Pac J Cancer Prev. 2011;12(11):2943-6.

3. Lestari AAW, Prabawa IPY, Wiranata S, Supadmanaba IGP. High eosinophils lymphocyte ratio (ELR) related with subtype of breast cancer in Sanglah General Hospital, Bali. Annals of Oncology. 2018;29(Suppl_9)

4. Wahidin M, Noviani R, Hermawan S, Andriani V, Ardian A, Djarir H. Population-based cancer registration in Indonesia. Asian Pac J Cancer Prev. 2012;13(4):1709-10.

5. Akhigbe AO, Omuemu VO. Knowledge, attitudes and practice of breast cancer screening among female health workers in a Nigerian urban city. BMC Cancer. 2009;9:203.

6. Ahmed F, Mahmud S, Hatcher J, Khan SM. Breast cancer risk factor knowledge among nurses in teaching hospitals of Karachi, Pakistan: a cross-sectional study. BMC Nurs. 2006;5:6.

7. Karayurt O, Ozmen D, Cetinkaya AC. Awareness of breast cancer risk factors and practice of breast self-examination among high school students in Turkey. BMC Public Health. 2008;8:359

8. Ranasinghe HM, Ranasinghe N, Rodrigo C, Seneviratne Rde A, Rajapakse S. Awareness of breast cancer among adolescent girls in Colombo, Sri Lanka: a school-based study. BMC Public Health. 2013;13:1209.

9. Isara AR, Ojedokun CI. Knowledge of breast cancer and practice of breast self examination among female senior secondary school students in Abuja, Nigeria. J Prev Med Hyg. 2011;52(4):186-90.

10. Montazeri A, Vahdaninia M, Harirchi I, Harirchi AM, Sajadian A, Khaleghi F. Breast cancer in Iran: need for greater women awareness of warning signs and effective screening methods. Asia Pac Fam Med. 2008;7(1):6.

11. Sait WA, Al-Amoudi SM, Tawtai DA, Abduljabbar HS. The knowledge of breast cancer among young Saudi females. Saudi Med J. 2010;31(11):1242-4. 
12. Allam MF, Abd Elaziz KM. Evaluation of the level of knowledge of Egyptian women of breast cancer and its risk factors. A cross sectional study. J Prev Med Hyg. 2012;53(4):195-8

13. Salaudeen AG, Akande TM, Musa OI. Knowledge and attitudes to breast cancer and breast self examination among female undergraduates in a state in Nigeria. Eur J Soc Sci. 2009;7(3):157-64.

14. McPherson K, Steel CM, Dixon JM.. ABC of breast diseases: breast cancer-epidemiology, risk factors, and genetics BMJ. 2000;321(7261):624-8.

15. Milaat WA. Knowledge of secondary-school female students on breast cancer and breast self-examination in Jeddah, Saudi Arabia. East Mediterr Health J. 2000;6(2-3):338-44.
16. Okobia $\mathrm{MN}$, Bunker $\mathrm{CH}$, Okonofua $\mathrm{FE}$, Osime U. Knowledge, attitude and practice of Nigerian women towards breast cancer: a cross-sectional study. World J Surg Oncol. 2006;4:11.

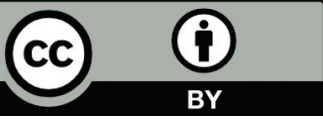

This work is licensed under a Creative Commons Attribution 